\title{
The Effect of Sodium Hyaluronate on the Corneal Biomechanics of Patients with Cataract and Dry Eye Before Operation
}

\author{
Nan Chen \\ Jin-Song Zhang \\ Tian-Xiao Zhang \\ Yu-Shuang Shao \\ Fan Zhang
}

Department of Ophthalmology, The Fourth Affiliated Hospital of China Medical University, Ophthalmological Center of China Medical University, Key Laboratory of Ophthalmology, China Medical University, Shenyang, I I0005, Liaoning, People's Republic of China
Correspondence: Fan Zhang Department of Ophthalmology, The Fourth Affiliated Hospital of China Medical University, Ophthalmological Center of China Medical University, Key Laboratory of Ophthalmology, China Medical University, Shenyang, I I0005, Liaoning, People's Republic of China Tel +86 I8704088002

Email zhangfan66_nn@I63.com
Objective: The aim of this study is to analyze the effect of the artificial tear drop administration time on the regularity of the corneal surface in patients with dry eye.

Methods: Patients with cataract who were admitted to the hospital from January 2018 to December 2018 were divided into four groups (A, B, C, and D) based on their grade of noninvasive tear break-up time (NIBUT) and the concentration of the eye drops used. Groups $A$ and $C$ were classified as NIBUT grade 1 (NIBUTf of 6-9 $\mathrm{s}$ and NIBUTav of 8-13 s), and groups B and D were classified as NIBUT grade 2 (NIBUTf of $<5 \mathrm{~s}$ and NIBUTav of $\leq 7 \mathrm{~s}$ ). Groups $\mathrm{A}$ and $\mathrm{B}$ received $0.1 \%$ sodium hyaluronate eye drops, and groups $\mathrm{C}$ and $\mathrm{D}$ received $0.3 \%$ sodium hyaluronate eye drops.

Results: In group A, there was a significant increase $(p<0.05)$ in the surface regularity index (SRI) and the surface asymmetry index (SAI) measured $1 \mathrm{~s}$ after eye drop administration. In group $B$, there was a significant decrease $(p<0.05)$ in the SRI and the SAI measured $1 \mathrm{~s}$ and 5 and $10 \mathrm{~min}$ after eye drop administration. In group $\mathrm{C}$, there was a significant increase $(\mathrm{p}<0.05)$ in the astigmatism degree, SRI, SAI, and irregular astigmatism index (IAI) measured $1 \mathrm{~s}$ after eye drop administration. There was a significant decrease $(p<0.05)$ in potential visual acuity (PVA). In group D, there was a significant increase in the IAI and Q value (parameters of aspheric characteristics of cornea, corneal $Q$ value) measured $1 \mathrm{~s}$ after eye drop administration as well as a significant decrease in PVA $(\mathrm{p}<0.05)$.

Conclusion: The use of $0.1 \%$ sodium hyaluronate eye drops in patients with dry eye aid the temporary recovery of corneal surface regularity and the stability of tear film. The $0.1 \%$ sodium hyaluronate had a significant effect for the first $10 \mathrm{~min}$ after treatment.

Keywords: dry eye, corneal topography, corneal surface regularity, tear film, sodium hyaluronate

\section{Introduction}

Dry eye is the most common clinically observed ocular surface disease. Symptoms of dry eye include burning, itching, foreign body sensation, and blurred and fluctuating vision. These symptoms may damage the ocular surface and negatively affect the patient's quality of life. ${ }^{1-3}$ Previous studies suggest that visual disorders in patients with dry eye are primarily the result of an increase in corneal surface irregularities and reduction in tear film stability. The tear film not only nourishes and protects the ocular surface, but also forms a smooth optical interface beneficial to clear retinal imaging on the corneal surface. ${ }^{4-7}$ With the development of cataract surgery and intraocular lens technology, a greater potential for the recovery of 
visual quality after cataract surgery has appeared. The regularity of the corneal surface is an important metric for determining a patient's intraocular lens power prior to cataract surgery. It is important to stabilize the tear film and enhance corneal regularity before surgery.

Dry eye is one of the most common clinically observed ocular surface diseases. An epidemiological survey carried out in Salisbury, Maryland found that as many as $15 \%$ of individuals aged over 65 years experienced dry eye. ${ }^{8}$ The traditional ways of diagnosing and evaluating dry eye, such as the tear secretion test and tear film break-up time measurement, produce variable results and lead to discomfort in the examinee's ocular surface. ${ }^{9,10}$ In recent years, ophthalmic examination methods, including corneal topography and ocular surface analysis, have become widely used. These methods provide new ways of diagnosing and evaluating dry eye. ${ }^{11}$ However, there has not yet been an in-depth study of the impact of artificial tears on changes in optical properties in patients with dry eye. In the present study, a noninvasive ocular surface analyzer (OCULUS Keratograph; OCULUS, Wetzlar, Germany) and a corneal topographer (OPD-Scan III; NIDEK Co., Ltd., Tokyo, Japan) were used to analyze and evaluate the effect of the concentration and administration time of sodium hyaluronate eye drops on corneal surface regularity in patients with dry eye.

\section{Materials and Methods}

\section{General Data}

Dry eye classification was performed on 104 patients with cataract who were admitted to the hospital from January 2018 to December 2018. The members of the entire patient group were aged 50-81 y, with an average age of $65.05 \pm 7.59 \mathrm{y}$. The patients (124 eyes) were divided on the basis of noninvasive tear break-up time (NIBUT), as measured prior to surgery by the OCULUS Keratograph noninvasive ocular surface analyzer. Next, they were randomly selected to receive either $0.1 \%$ or $0.3 \%$ sodium hyaluronate eye drops. Group A comprised 31 cases (33 eyes), with an average age of $66.79 \pm 7.46$ y. Group B comprised 20 cases (30 eyes), with an average age of $64.57 \pm 8.34$ y. Group $\mathrm{C}$ comprised 28 cases (31 eyes), with an average age of $64.33 \pm 6.59$ y. Group D comprised 25 cases (30 eyes), with an average age of $65.05 \pm 7.58 \mathrm{y}$.

None of the patients in the four groups exhibited signs of a condition that could increase tear secretion, namely chronic dacryocystitis and abnormalities in the ocular surface structure. The patients had no history of eye surgery or trauma and had never worn corneal contact lenses or used artificial tears or other drugs affecting ocular surface function in the previous six months. Patients with corneal irregularities of $\geq 2.0 \mathrm{~mm}$ (relatively high irregular astigmatism) were excluded from the study.

The study was conducted in accordance with the Declaration of Helsinki (as revised in 2013). The study was approved by the ethics committee of the Fourth Affiliated Hospital of China Medical University, and informed consent was taken from each patient.

\section{Apparatus and Methods}

(1) Inspection via noninvasive ocular surface analysis: the OCULUS Keratograph noninvasive ocular surface analyzer (OCULUS, Wetzlar, Germany) was used to inspect the patients' eyes. In every patient, each eye was inspected twice by the same technician, and the higher-quality images were selected for analysis. The two inspections were separated by an interval of $30 \mathrm{~min}$ so that the data would not be affected by patient fatigue. The NIBUT was recorded and graded for each patient. The grading criteria were as follows: (i) no dry eye (grade 0) - first NIBUT (NIBUTf) of $\geq 10$ s and average NIBUT (NIBUTav) of $\geq 14$ s; (ii) suspected dry eye (grade 1) - NIBUTf of 6-9 s and NIBUTav of 8-13 s; (iii) dry eye (grade 2) - NIBUTf of $<5 \mathrm{~s}$ and NIBUTav of $\leq 7 \mathrm{~s}$. The humidity and temperature of the inspection room were kept constant. (2) Examination via corneal topography: the NIDEK OPD-Scan III corneal topographer (NIDEK, Tokyo, Japan) was used to examine the patients' eyes. In every patient, each eye was inspected by the same technician. The technician recorded the average corneal curvature, degree of astigmatism, Q value (degree of corneal asphericity), surface regularity index (SRI), surface asymmetry index (SAI), irregular astigmatism index (IAI), and potential visual acuity (PVA). The OPD-Scan III recorded each measurement in every patient prior to eye drop administration and $1 \mathrm{~s}$ and 5, 10, 15, 20, 30, 60, and 120 min after eye drop administration. (3) Group A (31 cases, 33 eyes): the patients were classified as NIBUT grade 1 with symptoms of dry eye and treated with $0.1 \%$ sodium hyaluronate eye drops. Group B (20 cases, 30 eyes): the patients were classified as NIBUT grade 2 with symptoms of dry eye and treated with $0.1 \%$ sodium hyaluronate eye drops. Group C (28 cases, 31 eyes): the patients were classified as NIBUT grade 1 with symptoms of dry eye and treated with $0.3 \%$ sodium hyaluronate eye drops. Group 
D ( 25 cases, 30 eyes): the patients were classified as NIBUT grade 2 with symptoms of dry eye and treated with $0.3 \%$ sodium hyaluronate eye drops. (4) The patients in the present study all volunteered to participate and gave their written informed consent. The patients did not use any drugs before the study. During the interval between the two inspections, the patients closed their eyes and rested in order to avoid inaccurate data due to fatigue.

\section{Statistical Analysis}

The SPSS 17.0 software (IBM Corp., Armonk, NY, USA) was used to analyze the data. A one-way analysis of variance was used each time to compare the indices. If the homogeneity of variance was satisfied, a significant difference $t$-test was performed. Otherwise, Dunnett's $t$-test was used. A $p$ value of $<0.05$ was considered statistically significant.

\section{Results}

\section{Comparison of the Characteristics in Patients Before Treatment with Sodium Hyaluronate Eye Drops}

There was no statistical difference in the average age of the patients between the four groups $(p>0.05)$. There was also no significant difference between groups $\mathrm{A}$ and $\mathrm{C}$ or groups $\mathrm{B}$ and $\mathrm{D}$ in the examination results prior to treatment with sodium hyaluronate eye drops $(\mathrm{p}>0.05)$.

\section{Comparison of the Indices for Group a Before and After Treatment with 0.1\% Sodium Hyaluronate Eye Drops}

There was no statistically significant difference in the average corneal curvatures, degrees of astigmatism, Q values, or IAIs measured before and after treatment. The SRI increased
$1 \mathrm{~s}$ after treatment and was significantly different from the values recorded before treatment and the values recorded 5 , $10,15,20,30,60$, and 120 min after treatment $(p<0.05$, Table 1). The SAI increased $1 \mathrm{~s}$ and 5 min after treatment and was significantly different from the values recorded before treatment and the values recorded 10, 15, 20, 30, 60 , and $120 \mathrm{~min}$ after treatment $(\mathrm{p}<0.05$, Table 1$)$. These results show that the corneal surface regularity of patients with suspected dry eye (NIBUT grade 1) decreased after treatment with $0.1 \%$ sodium hyaluronate eye drops and then returned to the pre-treatment level. It is possible that this initial decrease took place due to part of the tear film thickening after the application of the sticky eye drops to the original, relatively stable tear film, resulting in uneven tear film distribution and affecting cornea regularity.

\section{Comparison of the Indices for Group B Before and After Treatment with 0.1\% Sodium Hyaluronate Eye Drops}

There was no statistically significant difference in the average corneal curvatures, degrees of astigmatism, $Q$ values, or IAIs measured before and after treatment. The SRI and SAI both decreased $1 \mathrm{~s}$ and 5 and $10 \mathrm{~min}$ after treatment, and they were significantly different from the values recorded before treatment and the values recorded 15, 20,30,60, and 120 min after treatment $(\mathrm{p}<$ 0.05 , Table 2). These results show that the corneal surface regularity of patients with dry eye (NIBUT grade 2) initially improved after treatment with $0.1 \%$ sodium hyaluronate eye drops but decreased again 15 min after treatment. This pattern of change suggests that the $0.1 \%$ sodium hyaluronate eye drops have a degree of viscosity that initially aided the regular recovery of the cornea. However, this effect gradually weakened with time.

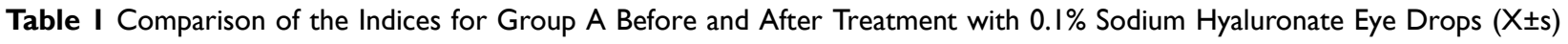

\begin{tabular}{|c|c|c|c|c|c|c|c|}
\hline Time & Corneal Curvature & Astigmatism & Q Value & SRI & SAI & IAI & PVA \\
\hline Before treatment & $44.29 \pm 1.46$ & $-1.07 \pm 0.76$ & $-0.18 \pm 0.18$ & $0.56 \pm 0.24$ & $0.47 \pm 0.15$ & $0.48 \pm 0.04$ & $1.15 \pm 0.15$ \\
\hline I sec after treatment & $43.95 \pm 1.56$ & $-1.32 \pm 0.94$ & $-0.03 \pm 0.37$ & $0.77 \pm 0.25$ & $0.59 \pm 0.16 * *$ & $0.5 \mathrm{I} \pm 0.05^{*}$ & $0.97 \pm 0.13$ \\
\hline 5 min after treatment & $44.28 \pm|.5|$ & $-1.02 \pm 0.83$ & $-0.14 \pm 0.33$ & $0.59 \pm 0.27$ & $0.57 \pm 0.47$ & $0.48 \pm 0.05^{*}$ & $1.14 \pm 0.19$ \\
\hline 10 min after treatment & $44.28 \pm 1.50$ & $-1.03 \pm 0.81$ & $-0.17 \pm 0.41$ & $0.52 \pm 0.25$ & $0.43 \pm 0.17$ & $0.47 \pm 0.05$ & $1.18 \pm 0.16$ \\
\hline 15 min after treatment & $44.30 \pm 1.48$ & $-\mid .0 I \pm 0.8 I$ & $-0.17 \pm 0.22$ & $0.5 I \pm 0.25$ & $0.45 \pm 0.16$ & $0.47 \pm 0.05$ & $1.17 \pm 0.19$ \\
\hline 20 min after treatment & $44.27 \pm|.5|$ & $-1.05 \pm 0.80$ & $-0.14 \pm 0.26$ & $0.52 \pm 0.28$ & $0.46 \pm 0.19$ & $0.47 \pm 0.05$ & $1.14 \pm 0.16$ \\
\hline 30 min after treatment & $44.29 \pm 1.48$ & $-1.03 \pm 0.76$ & $-0.24 \pm 0.44$ & $0.53 \pm 0.33$ & $0.47 \pm 0.18$ & $0.47 \pm 0.05$ & $1.16 \pm 0.17$ \\
\hline $60 \mathrm{~min}$ after treatment & $44.28 \pm 1.53$ & $-1.13 \pm 0.87$ & $-0.17 \pm 0.24$ & $0.53 \pm 0.27$ & $0.46 \pm 0.21$ & $0.47 \pm 0.04$ & $1.15 \pm 0.17$ \\
\hline 120 min after treatment & $44.28 \pm 1.48$ & $-1.00 \pm 0.8 \mid$ & $-0.22 \pm 0.38$ & $0.53 \pm 0.25$ & $0.45 \pm 0.16$ & $0.47 \pm 0.05$ & $1.15 \pm 0.16$ \\
\hline
\end{tabular}

Notes: For all preparations. * and $* *$ Indicate significant correlation and correlation at $\mathrm{P}<0.05$ level of repeated measurement $\mathrm{ANOVA}$, respectively. $\mathrm{P}<0.0 \mathrm{I}$ level was significantly correlated with the following table. 


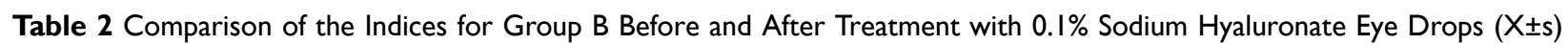

\begin{tabular}{|l|l|l|l|l|l|l|l|}
\hline Time & Corneal Curvature & Astigmatism & Q Value & SRI & SAI & IAI & PVA \\
\hline Before treatment & $44.56 \pm 1.44$ & $-0.97 \pm 0.88$ & $-0.57 \pm 0.75$ & $0.63 \pm 0.14$ & $0.58 \pm 0.11$ & $0.47 \pm 0.04$ & $1.13 \pm 0.10$ \\
I sec after treatment & $44.38 \pm 1.16$ & $-0.96 \pm 0.83$ & $0.05 \pm 0.88$ & $0.51 \pm 0.17^{*}$ & $0.45 \pm 0.094^{*}$ & $0.46 \pm 0.037$ & $1.15 \pm 0.12$ \\
5 min after treatment & $44.61 \pm 1.35$ & $-0.84 \pm 0.83$ & $-0.61 \pm 0.96$ & $0.52 \pm 0.17^{*}$ & $0.49 \pm 0.09 *$ & $0.45 \pm 0.062$ & $1.15 \pm 0.12$ \\
I0 min after treatment & $44.59 \pm 1.54$ & $-0.72 \pm 0.78$ & $-0.62 \pm 1.13$ & $0.47 \pm 0.12^{*}$ & $0.45 \pm 0.11 *$ & $0.45 \pm 0.05$ & $1.15 \pm 0.09$ \\
I 5 min after treatment & $44.59 \pm 1.48$ & $-0.88 \pm 0.74$ & $-0.12 \pm 0.45$ & $0.59 \pm 0.15$ & $0.54 \pm 0.15$ & $0.46 \pm 0.04$ & $1.15 \pm 0.09$ \\
20 min after treatment & $44.59 \pm 1.54$ & $-1.00 \pm 0.72$ & $-0.34 \pm 0.54$ & $0.64 \pm 0.116$ & $0.51 \pm 0.13$ & $0.46 \pm 0.039$ & $1.13 \pm 0.10$ \\
30 min after treatment & $44.53 \pm 1.54$ & $-0.94 \pm 0.88$ & $-0.33 \pm 0.46$ & $0.60 \pm 0.14$ & $0.57 \pm 0.11$ & $0.46 \pm 0.044$ & $1.13 \pm 0.10$ \\
60 min after treatment & $44.72 \pm 1.48$ & $-0.72 \pm 1.06$ & $-0.56 \pm 1.22$ & $0.56 \pm 0.19$ & $0.50 \pm 0.124$ & $0.45 \pm 0.04$ & $1.13 \pm 0.10$ \\
I 20 min after treatment & $44.56 \pm 1.49$ & $-0.78 \pm 1.21$ & $-0.07 \pm 0.09$ & $0.65 \pm 0.266$ & $0.54 \pm 0.14$ & $0.46 \pm 0.05$ & $1.10 \pm 0.15$ \\
\hline
\end{tabular}

Notes: For all preparations. *Indicate significant correlation at $\mathrm{P}<0.05$ level of repeated measurement ANOVA, $\mathrm{P}<0.0 \mathrm{I}$ level was significantly correlated with the following table.

\section{Comparison of the Indices for Group C Before and After Treatment with 0.3\% Sodium Hyaluronate Eye Drops}

There was no statistically significant difference in the average corneal curvatures or $\mathrm{Q}$ values measured before and after treatment. The degree of astigmatism and the IAI increased $1 \mathrm{~s}$ after treatment, while the PVA decreased 1 $\mathrm{s}$ after treatment. Each of these values was significantly different to the values recorded before treatment and the values recorded 5, 10, 15, 20, 30, 60, and 120 min after treatment $(\mathrm{p}<0.05$, Table 3$)$. The degree of astigmatism returned to its pre-treatment level $5 \mathrm{~min}$ after treatment, and the IAI and the PVA returned to their pre-treatment levels $10 \mathrm{~min}$ after treatment. The SRI and the SAI increased by a statistically significant degree $1 \mathrm{~s}$ after treatment $(\mathrm{p}<0.05$, Table 3$)$. However, both returned to their pre-treatment levels $10 \mathrm{~min}$ after treatment. These results show that the corneal surface regularity of patients with suspected dry eye (NIBUT grade 1) temporarily decreased after treatment with $0.3 \%$ sodium hyaluronate eye drops. This temporary decrease may be the result of the highly viscous eye drops not only being strongly retained on the surface of the eye, but also increasing the amount of tear fluid. After the eye drops were applied to the original, relatively stable tear film, part of the tear film thickened noticeably, resulting in uneven tear film distribution and affected cornea regularity.

\section{Comparison of the Indices for Group D Before and After Treatment with 0.3\% Sodium Hyaluronate Eye Drops}

The IAI increased $1 \mathrm{~s}$ after treatment, while the PVA decreased $1 \mathrm{~s}$ after treatment. Both of these values were significantly different from the values recorded before and after treatment $(\mathrm{p}<0.05$, Table 4). The $\mathrm{Q}$ value increased 1 $\mathrm{s}$ after treatment. This value was significantly different from the values recorded before treatment and the values recorded $5,10,15,20,30,60$, and 120 min after treatment $(\mathrm{p}<0.05$, Table 4). There was no statistically significant difference in the SRI or SAI, as measured before and after treatment. This

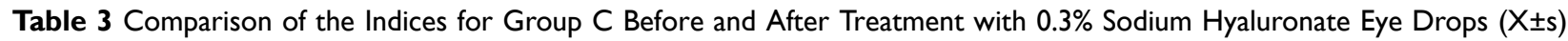

\begin{tabular}{|c|c|c|c|c|c|c|c|}
\hline Time & Corneal Curvature & Astigmatism & Q Value & SRI & SAI & IAI & PVA \\
\hline Before treatment & $44.06 \pm 1.04$ & $-0.88 \pm 0.49$ & $-0.28 \pm 0.26$ & $0.53 \pm 0.22$ & $0.4 I \pm 0.08$ & $0.47 \pm 0.04$ & $1.17 \pm 0.11$ \\
\hline I sec after treatment & $43.92 \pm 1.24$ & $-1.36 \pm 0.80 *$ & $-0.15 \pm 0.84$ & $0.89 \pm 0.29 *$ & $0.67 \pm 0.25^{*}$ & $0.5 \pm 0.06 *$ & $0.98 \pm 0.19 * *$ \\
\hline 5 min after treatment & $44.08 \pm 1.07$ & $-|| I \pm 0.8 \mid$. & $-0.13 \pm 0.43$ & $0.77 \pm 0.29$ & $0.52 \pm 0.21$ & $0.49 \pm 0.04$ & $1.06 \pm 0.15$ \\
\hline $10 \mathrm{~min}$ after treatment & $44.06 \pm 1.12$ & $-0.93 \pm 0.77$ & $-0.24 \pm 0.33$ & $0.66 \pm 0.26$ & $0.49 \pm 0.17$ & $0.48 \pm 0.03$ & $1.11 \pm 0.12$ \\
\hline $15 \mathrm{~min}$ after treatment & $44.14 \pm 1.10$ & $-0.92 \pm 0.50$ & $-0.29 \pm 0.38$ & $0.67 \pm 0.25$ & $0.46 \pm 0.15$ & $0.48 \pm 0.04$ & $I . I I \pm 0.14$ \\
\hline $20 \mathrm{~min}$ after treatment & $44.00 \pm 1.05$ & $-0.89 \pm 0.62$ & $-0.25 \pm 0.29$ & $0.62 \pm 0.22$ & $0.42 \pm 0.09$ & $0.47 \pm 0.03$ & $1.14 \pm 0.15$ \\
\hline $30 \mathrm{~min}$ after treatment & $44.07 \pm 1.09$ & $-0.93 \pm 0.58$ & $-0.20 \pm 0.229$ & $0.58 \pm 0.28$ & $0.45 \pm 0.14$ & $0.47 \pm 0.04$ & $1.16 \pm 0.17$ \\
\hline $60 \mathrm{~min}$ after treatment & $44.09 \pm 1.10$ & $-0.94 \pm 0.56$ & $-0.24 \pm 0.24$ & $0.57 \pm 0.19$ & $0.43 \pm 0.08$ & $0.46 \pm 0.03$ & $1.17 \pm 0.13$ \\
\hline 120 min after treatment & $44.05 \pm 1.10$ & $-1.02 \pm 0.68$ & $-0.23 \pm 0.23$ & $0.62 \pm 0.25$ & $0.45 \pm 0.14$ & $0.47 \pm 0.04$ & $1.13 \pm 0.16$ \\
\hline
\end{tabular}

Notes: For all preparations. * and **Indicate significant correlation and correlation at $\mathrm{P}<0.05$ level of repeated measurement ANOVA, respectively. $\mathrm{P}<0.0 \mathrm{I}$ level was significantly correlated with the following table. 
suggests that the viscosity and other physical and chemical properties of the high-concentration sodium hyaluronate had a greater impact than its surface activity and surface tension. This finding is consistent with the results of Watanabe et al. ${ }^{12}$

\section{Comparison of Indices Changes in the Four Groups' (A, B, C, and D, Figure I)}

There was no significant change in the average corneal curvature of any of the four groups, as measured before and after treatment with sodium hyaluronate eye drops (Figure 1A). The degree of corneal astigmatism increased to varying degrees in each group $1 \mathrm{~s}$ after treatment. The degree of astigmatism then decreased gradually in each group, with the largest decreases occurring between 1 $\mathrm{s}$ and 5 min after treatment (Figure 1B). In group D, the $\mathrm{Q}$ value increased significantly $1 \mathrm{~s}$ after treatment, reaching positive values before gradually returning to its original level 5 min after treatment (Figure $1 \mathrm{C}$ ). In groups A, C, and D, the SRI increased $1 \mathrm{~s}$ after treatment; in groups $\mathrm{A}$ and $\mathrm{C}$, the SRI reached its maximum value $1 \mathrm{~s}$ after treatment and then decreased to pre-treatment levels $10 \mathrm{~min}$ after treatment. In group B, the SRI decreased between $1 \mathrm{~s}$ and $10 \mathrm{~min}$ after treatment and increased correspondingly 15 min after treatment (Figure 1D). In groups A, C, and D, the SAI increased $1 \mathrm{~s}$ after treatment. In groups $\mathrm{A}$ and $\mathrm{C}$, the SAI reached its maximum value $1 \mathrm{~s}$ after treatment and then decreased to its pre-treatment level $10 \mathrm{~min}$ after treatment. In group B, the SAI decreased between $1 \mathrm{~s}$ and $10 \mathrm{~min}$ after treatment and increased correspondingly $15 \mathrm{~min}$ after treatment (Figure 1E). In groups A, C, and D, the IAI increased 1 $s$ after treatment. However, there was no obvious change in the IAI of group B, as measured before and after treatment (Figure 1F). In groups A, C, and D, the PVA decreased 1 $\mathrm{s}$ after treatment and returned to pre-treatment levels $10 \mathrm{~min}$ after treatment. In contrast, there was no obvious change in the PVA of group B, as measured before and after treatment (Figure 1G).

\section{Discussion}

When a patient has an unstable tear film or is suffering from dry eye, the symptoms of eye-burn and foreign body sensation can be accompanied by blurred and fluctuating vision. These changes in vision may be related to unstable tear film, irregular corneal surfaces, higher SRI or SAI, and lower PVA, all of which characterize patients with dry eye. ${ }^{13}$ On the basis of clinical practice, Sheppard ${ }^{14}$ suggests that attention should be paid to the presence of dry eye before proceeding with cataract surgery since this condition may affect the healing of the wound, result in changes in refractive power, and lead to the inaccurate measurement of corneal astigmatism. In doing so, dry eye may prevent cataract surgery from achieving its expected effect. In addition, the accuracy of many of the instruments commonly used prior to cataract surgery also depends on tear film stability and corneal surface regularity. As a result, it is very important that the tear film is stabilized and the corneal surface regularity restored before cataract surgery takes place.

Corneal topography provides a visual representation of the corneal surface, and software can be used to determine its parameters, including the corneal curvature, degree of corneal astigmatism, Q value, SRI, SAI, IAI, and PVA. Of these parameters, higher SRI and SAI indicate greater corneal surface irregularity ${ }^{11}$ and lower PVA. Previous studies have suggested that the SRI, SAI, IAI, PVA, $\mathrm{Q}$ value, and degree of corneal astigmatism are closely correlated with a reduction in vision quality in patients with dry eye. ${ }^{14-16}$ Thus, these parameters may be used as reference indices for the diagnosis of dry eye, which will

Table 4 Comparison of the Indices for Group D Before and After Treatment with $0.3 \%$ Sodium Hyaluronate Eye Drops (Xts)

\begin{tabular}{|c|c|c|c|c|c|c|c|}
\hline Time & Corneal Curvature & Astigmatism & Q Value & SRI & SAI & IAI & PVA \\
\hline Before treatment & $45.08 \pm 1.54$ & $-1.04 \pm 0.75$ & $-0.40 \pm 0.33$ & $0.63 \pm 0.29$ & $0.48 \pm 0.13$ & $0.49 \pm 0.05$ & $1.10 \pm 0.10$ \\
\hline I sec after treatment & $45.25 \pm 2.08$ & $-1.33 \pm 1.62$ & $0.29 \pm 0.93 *$ & $0.84 \pm 0.29$ & $0.69 \pm 0.41$ & $0.55 \pm 0.07 I^{*}$ & $0.93 \pm 0.26^{*}$ \\
\hline 5 min after treatment & $44.98 \pm 1.47$ & $-1.04 \pm 0.78$ & $-0.28 \pm 0.23$ & $0.79 \pm 0.30$ & $0.5 I \pm 0.17$ & $0.5 I \pm 0.06$ & $1.05 \pm 0.12$ \\
\hline $10 \mathrm{~min}$ after treatment & $45.04 \pm 1.50$ & $-0.79 \pm 0.38$ & $-0.23 \pm 0.21$ & $0.70 \pm 0.23$ & $0.46 \pm 0.14$ & $0.49 \pm 0.03$ & $1.07 \pm 0.10$ \\
\hline $15 \mathrm{~min}$ after treatment & $45.13 \pm 1.48$ & $-0.92 \pm 0.51$ & $-0.32 \pm 0.20$ & $0.75 \pm 0.32$ & $0.5 I \pm 0.15$ & $0.52 \pm 0.05$ & $1.05 \pm 0.13$ \\
\hline $20 \mathrm{~min}$ after treatment & $45.10 \pm 1.55$ & $-0.85 \pm 0.5 I$ & $-0.46 \pm 0.52$ & $0.70 \pm 0.32$ & $0.50 \pm 0.18$ & $0.49 \pm 0.05$ & $1.07 \pm 0.16$ \\
\hline $30 \mathrm{~min}$ after treatment & $44.8 I \pm I .40$ & $-1.42 \pm 1.25$ & $-0.46 \pm 0.65$ & $0.69 \pm 0.38$ & $0.60 \pm 0.34$ & $0.50 \pm 0.065$ & $1.02 \pm 0.20$ \\
\hline $60 \mathrm{~min}$ after treatment & $45.15 \pm 1.50$ & $-0.89 \pm 0.48$ & $-0.34 \pm 0.28$ & $0.83 \pm 0.42$ & $0.55 \pm 0.28$ & $0.50 \pm 0.06$ & $1.03 \pm 0.14$ \\
\hline 120 min after treatment & $45.13 \pm 1.38$ & $-1.33 \pm 1.29$ & $-0.16 \pm 0.27$ & $0.82 \pm 0.42$ & $0.7 I \pm 0.50$ & $0.5 I \pm 0.05$ & $0.95 \pm 0.24$ \\
\hline
\end{tabular}

Notes: For all preparations. *Indicate significant correlation at $\mathrm{P}<0.05$ level of repeated measurement ANOVA, $\mathrm{P}<0.0 \mathrm{I}$ level was significantly correlated with the following table. 


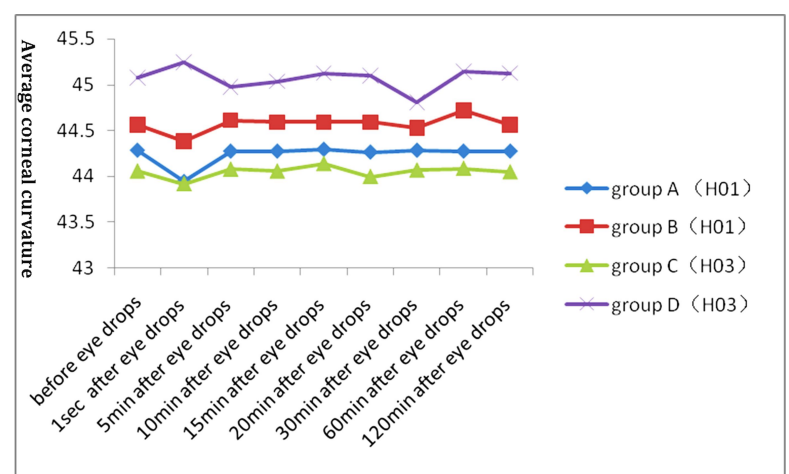

A

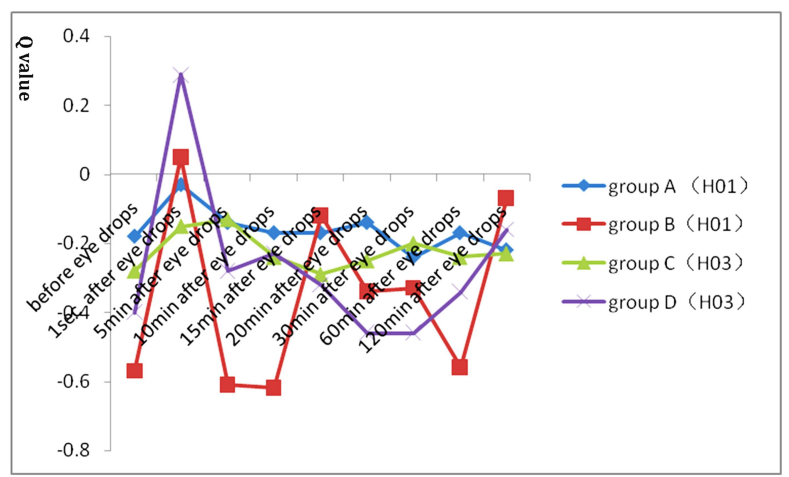

C

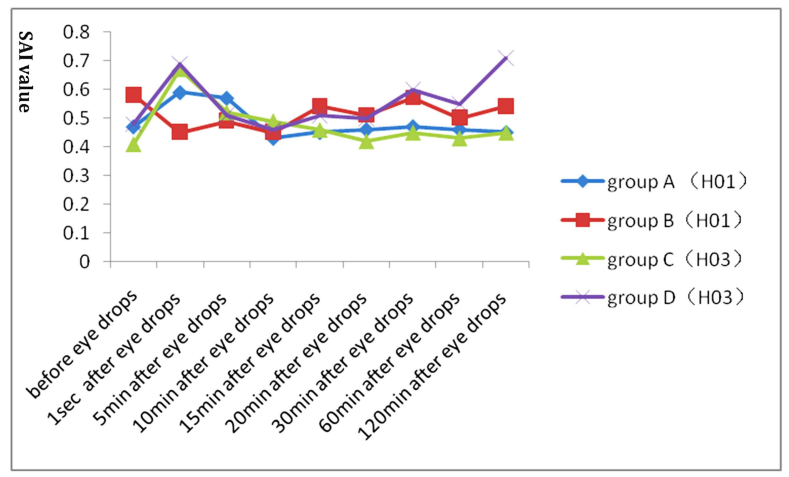

E

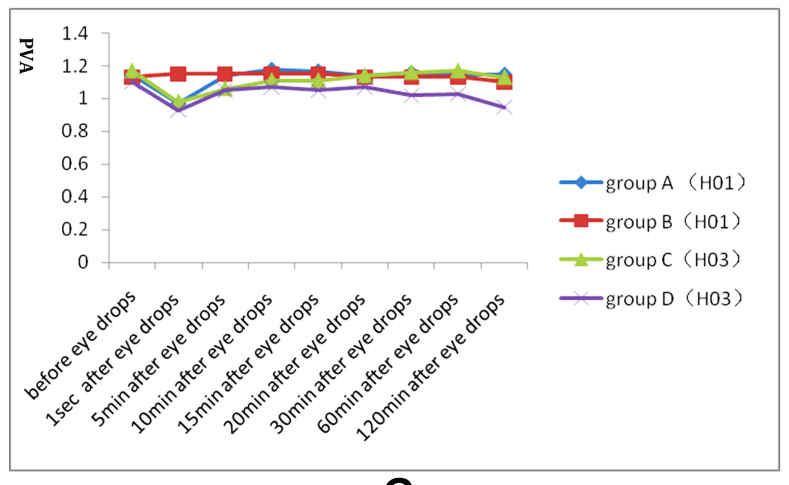

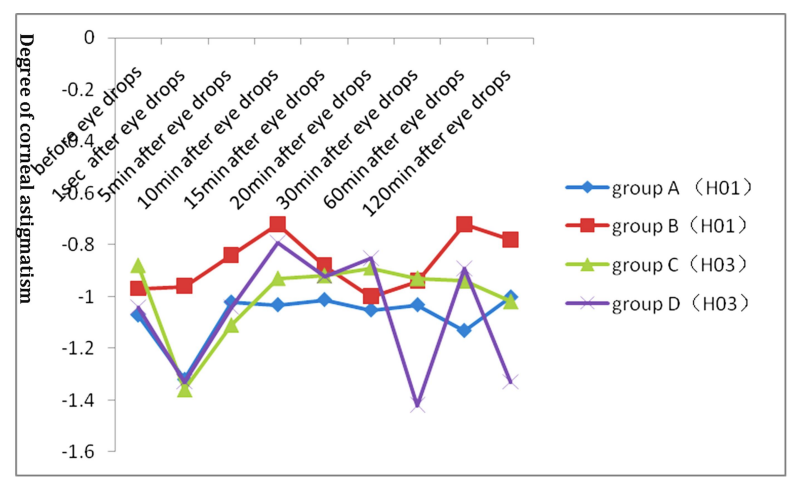

B
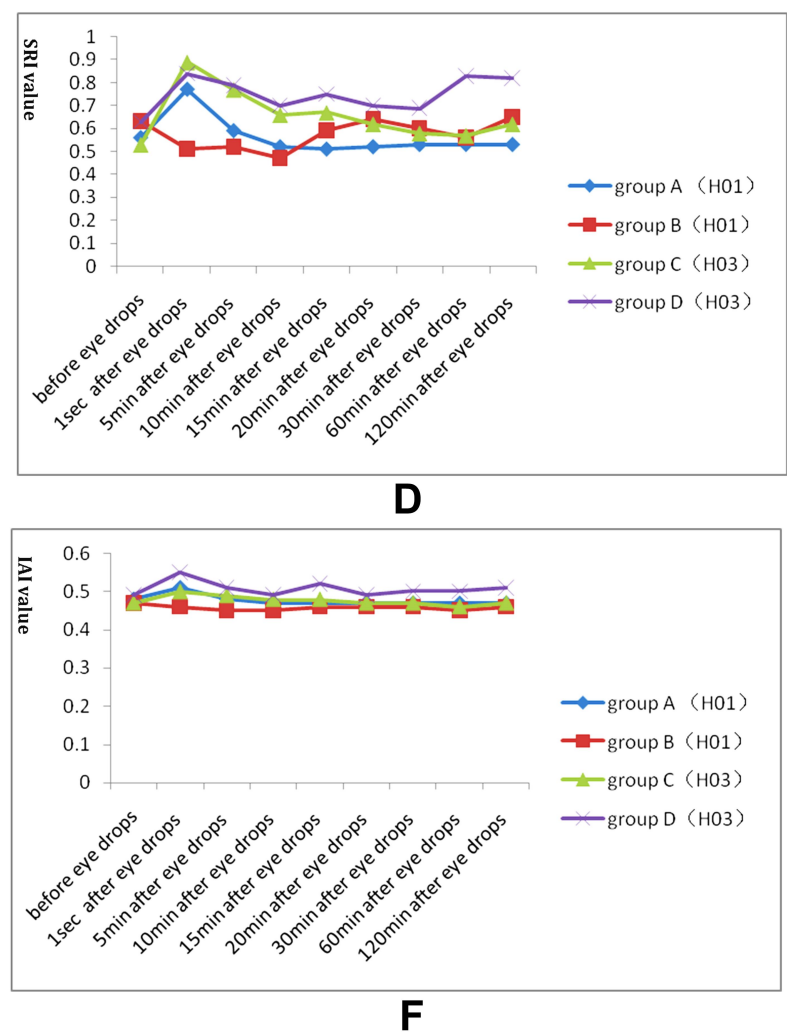

Figure I Changes of the indices before and after treatment in groups A, B, C, and D. Horizontal axis: before treatment, I sec, 5 min, 10 min, I5 min, 20 min, 30 min, 60 min, and 120 min after treatment. Longitudinal axis: average corneal curvature (A), degree of corneal astigmatism (B), Q value (C), SRI value (D), SAI value (E), IAI value (F), and PVA (G).

aid in the evaluation of patients with dry eye prior to cataract surgery, refraction surgery, and other operations, while also making it possible to judge the effects of artificial tears on tear film reconstruction more accurate. ${ }^{17}$ 
Sodium hyaluronate is a type of aminodextran with a viscoelastic rheology. Its relatively high viscosity can enhance tear film stability, improve liquid retention on the surface of the cornea, and increase corneal humidity. In addition, sodium hyaluronate can promote the migration and reparation of the corneal epithelial cells. As a result, sodium hyaluronate has become an important treatment for dry eye. ${ }^{18-20}$ Previous studies have reported that $0.1 \%$ sodium hyaluronate eye drops can significantly increase the height of the lacrimal river in $3 \mathrm{~min}$ and that $0.3 \%$ sodium hyaluronate eye drops, where the effect is concentration dependent, can do so in $5 \mathrm{~min}^{12}$ This indicates that sodium hyaluronate eye drops can increase the amount of tear fluid for a long period of time, where higher concentrations lead to better retention by the eye's surface. However, no previous study has evaluated corneal surface regularity or conducted a time-effect analysis of the visual function of patients with dry eye after treatment with sodium hyaluronate. The results of the present study suggest that $0.1 \%$ sodium hyaluronate may aid in the temporary recovery of corneal surface regularity and tear film stability in patients with dry eye. Because a highly significant effect was observed within 10 min of treatment, the use of $0.1 \%$ sodium hyaluronate may improve the accuracy of corneal biometry. Once $10 \mathrm{~min}$ elapsed in this study, the effect was not as obvious as before due to the decreasing levels of viscosity and elasticity. However, corneal regularity and corneal biometry accuracy may decrease in patients with a relatively stable tear film. In these patients, the tear film may become thickened and unevenly distributed after the application of the viscous eye drops. Because $0.3 \%$ sodium hyaluronate has an even higher viscosity than $0.1 \%$ sodium hyaluronate, it can cause a greater degree of thickening and uneven distribution of the tear film. Thus, for patients with dry eye, it is recommended to use low concentration sodium hyaluronate to increase the accuracy of measurement as much as possible. In the present study, no drugs were used that could interfere with the experimental results, and patients closed their eyes to rest during the interval between examinations to avoid the generation of inaccurate data.

\section{Conclusion}

As a result of the present study's relatively small sample size, the testing method had a lower degree of sensitivity and specificity, and further studies are needed in order to confirm the results. However, the present study still presents a quantitative evaluation of the effect of different concentrations of sodium hyaluronate on the temporary restoration of corneal surface regularity at different effective times and provides an objective basis for improving the accuracy of corneal biometry.

\section{Acknowledgments}

We are particularly grateful to all the people who have given us help on our article.

\section{Funding}

This study was funded by National Natural Science Foundation of China science Foundation for Youth (No. 81100700). The funding body had no role in the design of the study and collection, analysis, and interpretation of data and in writing the manuscript.

\section{Disclosure}

The authors declare that they have no competing interests.

\section{References}

1. Messmer EM. The pathophysiology, diagnosis, and treatment of dry eye disease. Dtsch Arztebl Int. 2015;112(5):71-82. doi:10.3238/ arztebl.2015.0071

2. Rouen PA, White ML. Dry eye disease: prevalence, assessment, and management. Home Healthc Now. 2018;36(2):74-83. doi:10.1097/ NHH.0000000000000652

3. Clayton JA, Longo DL. Dry eye. $N$ Engl J Med. 2018;378 (23):2212-2223. doi:10.1056/NEJMra1407936

4. Yokoi N, Georgiev GA. Tear-film-oriented diagnosis for dry eye. Jpn J Ophthalmol. 2019;63(2):127-136. doi:10.1007/s10384-018-00645-4

5. Koh S, Tung CI, Inoue Y, Jhanji V. Effects of tear film dynamics on quality of vision. $B r J$ Ophthalmol. 2018;102(12):1615-1620. doi:10.1136/bjophthalmol-2018-312333

6. Zhuang H, Xu JJ. Extended application of routine ophthalmic technology in dry eye. J Clin Exp Ophthalmol. 2009;11:1050-1053.

7. Liu ZG, Xie YH, Zhang M, Stephen C. The effect of artificial tears on corneal surface regularity in dry eye. Chin J Ophthalmol. 2000;36 (2):131-134.

8. Schein OD, Muñoz B, Tielsch JM, Bandeen-Roche K, West S. Prevalence of dry eye among the elderly. Am $J$ Ophthalmol. 1997;124:723-728.

9. Nichols KK, Mitchell GL, Zadnik K. The repeatability of clinical measurements of dry eye. Cornea. 2004;23(3):272-285. doi:10.1097/ 00003226-200404000-00010

10. Nichols KK, Nichols JJ, Mitchell GL. The lack of association between signs and symptoms in patients with dry eye disease. Cornea. 2004;23(8):762-770. doi:10.1097/01. ico.0000133997.07144.9e

11. Liu Z, Pflugfelder SC. Corneal surface regularity and the effect of artificial tears in aqueous tear deficiency. Ophthalmology. 1999;106 (5):939-943. doi:10.1016/S0161-6420(99)00513-8

12. Watanabe T, Kawashima M, Kawai M, Yamada M, Mashima Y. The effect of sodium hyaluronate eyedrops on tear meniscus height determined by fluorescein photography. Folia Ophthalmol Jpn. 2003;44:369-373.

13. Goto E, Yagi Y, Matsumoto Y, Tsubota K. Impaired functional visual acuity of dry eye patients. Am J Ophthalmol. 2002;133(2):181-186. doi:10.1016/S0002-9394(01)01365-4 
14. Song Y, Zhang L, Zhou SR. Effect of dry eye on corneal astigmatism after cataract surgery. Adv Ophthalmol. 2005;25127-25129.

15. Hao FQ, Zhang J, Liu JL, Liu YX, Li Y. Effect of artificial tear on ocular aberration and corneal topography in patients with dry eye. Chin J Pract Ophthalmol. 2009;27:763-765.

16. Jiang T, Xue CY, Huang ZP. Clinical observation of diffuse lamellar keratitis after excimer laser in situ keratomileusis. J Med Postgrad. 2003;16:600-601.

17. Yin J, Huang ZP, Yang LP, et al. The corneal topography of xerophthalmia is analytical. $J$ Med Postgrad. 2005;18:964-965.

18. You IC, Li Y, Jin R, Ahn M, Choi W, Yoon KC. Comparison of $0.1 \%$, $0.18 \%$, and $0.3 \%$ hyaluronic acid eye drops in the treatment of experimental dry eye. J Ocul Pharmacol Ther. 2018;34(8):557-564. doi:10.1089/jop.2018.0032
19. Park Y, Song JS, Choi CY, Yoon KC, Lee HK, Kim HS. A randomized multicenter study comparing $0.1 \%, 0.15 \%$, and $0.3 \%$ sodium hyaluronate with $0.05 \%$ cyclosporine in the treatment of dry eye. J Ocul Pharmacol Ther. 2017;33(2):66-72. doi:10.1089/ jop.2016.0086

20. Johnson ME, Murphy PJ, Boulton M. Effectiveness of sodium hyaluronate eyedrops in the treatment of dry eye. Graefes Arch Clin Exp Ophthalmol. 2006;244(1):109-112. doi:10.1007/s00417-005-0028-1

\section{Publish your work in this journal}

The International Journal of General Medicine is an international, peer-reviewed open-access journal that focuses on general and internal medicine, pathogenesis, epidemiology, diagnosis, monitoring and treatment protocols. The journal is characterized by the rapid reporting of reviews, original research and clinical studies across all disease areas. The manuscript management system is completely online and includes a very quick and fair peer-review system, which is all easy to use. Visit http://www.dovepress.com/ testimonials.php to read real quotes from published authors. 